of the Fair. The largest number of foreign buyers visiting the Fair will come from Holland; Germany is second on the list and Belgium, which was second last year, is third. Large contingents of buyers will also arrive from France, Denmark, Switzerland, the United States, Norway, Sweden, Poland, Czechoslovakia and Spain. From the British Empire countries, the largest number of buyers will come from the Irish Free State, with Canada next, followed by India, South Africa and Australia in that order. Altogether sixty-four countries will be represented.

\section{International Protection of Birds}

THE recently re-organised British National Section of the International Committee for Bird Preservation met on January 15 at the British Museum (Natural History). There were present Mr. Perey R. Lowe (chairman); Dr. F. H. A. Marshall (Royal Society); Mr. Hugh Gladstone and Mr. David Seth-Smith (Zoological Society of London); Dr. G. Carmichael Low (British Ornithologists' Union); Mrs. Frank E. Lomon and Mr. A. Holte Macpherson (Royal Society for the Protection of Birds); Mr. N. B. Kinnear and Mr. Hugh Whistler (National Trust); Mr. D. A. Bannerman and Mr. G. E. Lodge (Society for the Promotion of Nature Reserves); Mr. C. W. Hobley (Society for the Preservation of the Fauna of the Empire); and Miss Phyllis Barclay-Smith (hon. secretary). The chairman made reference to the great advance made by the International Committee for Bird Preservation during the past two years, and paid tribute to the pioneer work of its chairman, Dr. Gilbert Pearson, of the United States. Among the subjects which are engaging the activities of the British Section at the present moment are a proposed International Convention for the Preservation of Birds, to take the place of the Paris Convention of 1902, the further protection of the quail from an international point of view, and an investigation as to the actual status of wild duck in the British Isles. The question as to whether there may not be a serious decrease in the numbers of wild duck is giving rise to considerable anxiety to ornithologists and sportsmen.

\section{Modern Spectroscopy}

THE three Cantor lectures on the above subject, delivered by Prof. H. Dingle to the Royal Society of Arts in November and December 1934, have now been published (London: Royal Society of Arts, 1935. 2s. 6d.). They deal with the spectra of atoms, molecular and absorption spectra, and applications of spectroscopy. The first lecture outlines the main characteristics of atomic spectra, primarily from the experimental point of view. The second deals, in a rather more detailed manner, with band spectra; some indication is given of how these arise, and of their structure. The subject of absorption spectra is also touched upon. The non-physicist, to whom the lectures were primarily addressed, will find the third lecture, on the applications of spectroscopy, of particular interest and value, since it contains a good doal of matter not readily available elsewhere. The difficulties of qualitative and quantitative spectrum analysis are clearly set forth, and the present possibilities of such methods are indicated, some interesting examples being cited. This particular application of spectroscopy is, of course, older than any other, but unexpected obstacles to its general application were encountered at an early stage, and until recently the method has been neglected to such an extent that the very meaning of the term 'spectrum analysis' is apparently unfamiliar to some of the younger physicists of the present day, with whom it connotes the analysis of spectra, for physical purposes, instead of analysis by spectra for chemical purposes. Concerning the section devoted to astronomical spectroscopy, it need only be said that in lucidity and interest it is quite representative of the author's well-known writings on this subject. The text is well illustrated throughout by diagrams and reproductions of spectrum photographs. The lectures will without doubt appeal to a wide circle of readers, that is to say, all those who have no special knowledge of spectroscopy but wish to obtain a general idea of what it is about and what is its contribution to the general body of scientific knowledge.

\section{Rare and Standard Books on Engineering}

Messrs. Henry Sotheran, Ltd., have now issued part 2 of their Catalogue of Science and Technology, No. 3, an annotated and classified list of old, rare and standard works on "Fxact and Applied Science". This part enumerates books on mechanical and electrical engineering, conveniently arranged in appropriate sections, and includes publications throughout the period from the beginning of the sixteenth century down to recent years. Many famous volumes are mentioned-such as Papin's "New Digester" (1681) and the quaintly bombastic "Century of the Names and Scantlings of such Inventions as at present I can call to mind to have tried and perfected" of Edward Somerset, second Marquis of Worcester, whose work, if inclined towards perpetual motion, was genuinely moving in the direction of the steam engine. Gilbert's "de Magnete" (1600) is of great interest not only as being in Lord Kelvin's view "one of the finest examples of inductive philosophy that has ever been presented to the world", but also in that it contains the rarest of all autographs of men of science, that of Gilbert himself, the father of electrical science. Napier's "Deseriptio" (1614) and Newton's "Principia" (1687) are represented by first editions. As many of these books have been the possessions of outstanding men of science, their notes are of peculiar value. A copy of Silvanus Thompson's "Dynamo-Electric Machinery" (1886) is enriched "with very numerous MS. notes (often severely critical and sometimes sarcastic) by Oliver Heaviside, F.R.S.".

\section{Botany in the University of Sydney}

VoL. 2 of Botanical Reprints from the University of Sydney shows very valuable work in progress on characteristic groups of the Australian flora. A. Burges has a first paper upon the rust fungi of the Dominion, which deals most appropriately with the genus Uromycladium, in which six of the 